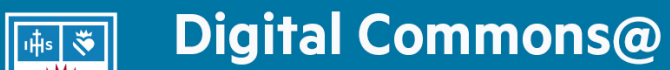

Loyola Marymount University

LMU Loyola Law School

\section{Cities and the Environment (CATE)}

\section{Portrayal of Interactions Between Humans and Coyotes (Canis latrans): Content Analysis of Canadian Print Media (1998-2010)}

Shelley M. Alexander

University of Calgary, smalexan@ucalgary.ca

Michael S. Quinn

University of Calgary, Quinn@ucalgary.ca

Follow this and additional works at: https://digitalcommons.Imu.edu/cate

\section{Recommended Citation}

Alexander, Shelley M. and Quinn, Michael S. (2012) "Portrayal of Interactions Between Humans and Coyotes (Canis latrans): Content Analysis of Canadian Print Media (1998-2010)," Cities and the Environment (CATE): Vol. 4: Iss. 1, Article 9.

Available at: https://digitalcommons.Imu.edu/cate/vol4/iss1/9

This Special Topic Article: Urban Wildlife is brought to you for free and open access by the Center for Urban Resilience at Digital Commons @ Loyola Marymount University and Loyola Law School. It has been accepted for inclusion in Cities and the Environment (CATE) by an authorized administrator of Digital Commons at Loyola Marymount University and Loyola Law School. For more information, please contact digitalcommons@lmu.edu. 


\section{Portrayal of Interactions Between Humans and Coyotes (Canis latrans): Content Analysis of Canadian Print Media (1998-2010)}

Print media is one form of public discourse that provides a means to examine human-coyote interactions. We conducted a content analysis of 453 articles addressing coyote events reported in the Canadian print media between 1998 and 2010. We found 119 articles about human-coyote interactions, of which 32 involved a report of coyote biting (26) or attempting to bite (6) a person. 108 articles were about coyotedogs and 32 about coyotes-cat interactions. Remaining articles were on topics unrelated to interactions (e.g. culls). Basing our analysis in grounded theory, we identified important descriptive and emotional themes surrounding these events. The most common words describing coyotes were: brazen, wiley, mangy, nuisance, wild and vicious. Interactions were described as attacks in 185 articles, while only 32 "attacks" were identified. Coyotes were portrayed as not natural in cities, as an invasive species, and more recently using language depicting criminal behaviour. Descriptions of coyotes killing or attacking people were inflammatory (e.g. savaged, ripped juts open), whereas descriptions of people killing coyotes were not (e.g. euthanized). Five emotional responses emerged describing humans involved in coyote interactions. Of these, statements of fear were most prevalent and yielded the richest understanding of perceptions about the risk of coyote-human interactions, including: fear for children's safety (73), fear for disease (44), fear for pet safety (43), and fear for self or others safety (35). Traumatic response was reported in 28 articles, while sadness and grief were described in 17 . Two other themes were: 1) animal welfare concerns, 2) frustration due to lack of agency response. Popular media plays a critical role in shaping public understanding and can influence people's emotional experiences, perceptions and management consequences. We highlight that coyotes are prejudiced (and stereotyped) based on the isolated and sensationalized incidents. Coyotes in particular elicit a wide range of emotional responses in people, and there is often a wide gap between perception and reality of risk when understanding whether it is possible for humans and coyotes to co-exist. Hence, there is a strong need for media literacy about the unintended or intended maligning of coyotes to the general public, as the consequence can be social amplification of risk and the unwarranted persecution of coyotes.

\section{Keywords}

coyotes, Canis latrans, content analysis, media, Canada, emotions, language 


\section{INTRODUCTION}

The coyote (Canis latrans) is the only canid to arise, adapt, and remain continuously in North America (Wang et al. 2008). Recently, coyotes have become an increasing management concern because their significant behavioural plasticity allows them to live in cities (Bekoff and Gese 2003). While this resilient character earned it a central, revered place in the culture and mythology of indigenous peoples from the Athabaskans of the far north to the Zapotecs of southern Mesoamerica (Dobie 1949, Cadieux 1983, Walker 1994), the European regime has subjected the coyote to extreme persecution:

For forty-five years, Uncle Sam has fought a war against coyotes ... and lost! In the years between 1937 and 1981, minions of the Fish and Wildlife Service scalped $3,612,220$ coyotes. The ears with a connecting strip of skin were sent to a central tallying point as proof of their "body count". In 1982 there were probably more coyotes in the United States than ever before. Don't tell me that we didn't lose that war (Cadieux 1983, p. 51).

Highly adaptable, coyotes can easily switch food resources and become conditioned to human food sources; in turn, this can lead to negative interactions with people and pets (Carbyn 1989, Gehrt 2004). Interactions deemed to be negative by humans result in significant challenges for managers, who must try to balance public perception of risks to human safety with maintaining critical ecological function. Extreme reactions to coyote attacks in cities spawn calls for widespread culls (Fox and Papouchis 2005, Berger 2006). Yet, on average, a review of media reports about coyote attacks in Canada showed that just less than 3 people per year were bitten by a coyote in Canada between 1995-2010 (Alexander and Quinn 2011).

The ecological role of coyotes in complex, social-ecological urban systems (Alberti 2008, Pickett et al. 2011a) is worth considering and maintaining, as the species have been found to have a critical role in ecosystem function (Crooks and Soule 1999, Bekoff and Gese 2003). Crooks and Soule (1999) argued that the presence of coyotes in cities can maintain breeding bird populations through the suppression of smaller carnivores, such as, mustelids and feral cats. Gehrt (2004) and Piccolo (2002) also theorized that coyotes may contribute to the regulation of white-tailed deer and Canada geese respectively. Maintaining this trophic function is predicted to be ecologically critical in urban systems that tend more towards bottom-up control (Faeth et al. 2005). Such ecological benefits underscore the need to strive for human-coyote coexistence (Baker and Timm 1998).

Despite the role coyotes have in urban ecosystems, they continue to be subject to widespread control and removal efforts. These efforts have proven largely ineffective due to the resilient life history characteristics of this species, a few of the most relevant of which are outlined here (Fox and Papouchis 2005). Coyote packs consist of related individuals and the pack sizes vary by geographic region or habitat types, and can produce litters of approximately six pups per year. They have a highly organized social system, and in theory only the alpha pair will reproduce. However, as with wolves, coyotes are serial monogamists; they may only breed with one individual, but that individual may change over time. And, when the population is under pressure from hunting, for example, social structure may break down, resulting in more 
and younger animals breeding to compensate for losses in the population (Bekoff et al. 1986). More specifically, whereas coyote females in an intact social system may normally breed between the ages of 2-4 years of age the age of first reproduction may be as early as 1 if the population is stressed. Research has documented this process, illustrating that widespread killing of coyotes alters social structure, changes breeding patterns, results in more pups being born and greater recruitment to the overall population of coyotes (Fox and Papouchis 2005). This effect can render control efforts useless for reducing numbers, and simultaneously may exacerbate conflict by creating a population favoring younger, less well socialized animals that are prone to exploit human sources of food. In Canada, coyotes continue to be the target of eradication programs despite the litany of failed efforts (Sandlos 1998). For example, it is estimated that 71,000 coyotes were killed in Saskatchewan between November 2009 and March 2010 in response to a provincial bounty of \$20/animal (Government of Saskatchewan 2010).

It would seem self-evident that the coyote is here to stay and we believe that efforts would be better directed toward achieving coexistence rather than eradication. Learning to live with coyotes in a "humane metropolis" (Pickett et al. 2011b) necessitates understanding their ecology, but perhaps more importantly, becoming more erudite with human perceptions, attitudes, values and behaviors toward them (Decker et al. 2001, Clark et al. 2005, BaruchMordo et al. 2009, Draheim et al. 2011, Johansson and Karlsson 2011). In fact, as Bekoff and Bexell (2010) remark, it is not the lack of ecological knowledge and data that leads to lost opportunities to co-exist with species like the coyote, "rather, losses are typically due to problems of human psychology, and social and cultural factors that result in the inadequate protection of animals and their habitats" (p.71).

Carnivores are particularly poignant with respect to human dimensions of wildlife issues in cities, because they elicit such strong emotional responses (Jacobs 2009, Draheim et al. 2011). Such responses can inform species' characterization, management and conservation (Johansson and Karlsson 2011). Coyotes, specifically, elicit a wide range of emotional responses in people and there is often a wide gap between public perception and the actual risk associated with coexistance (Alexander and Quinn 2011). These responses are frequently seen in media discourse (i.e., on tv or in print media). Print media offers a pervasive and rich venue for examining such public discourse and provides a window into how human-coyote interactions are portrayed. Reviewing these media stories yields valuable information about the incidence and outcomes of human-coyote interactions as well as insight into: the attitudes and perceptions people have about coyotes, the emotions elicited through the interaction, how best to manage both species and how the media may influence public perception (Bengston et al. 1999, Siemer et al. 2007). In particular, discourse analysis is said to improve our understanding of the human dimensions of coyote interactions (White and Gehrt 2009). As such, we used content analysis to explore how the media characterize coyote interactions with people and pets in Canada.

Media content analysis usually employs a systematic approach to understanding public communications (Bengston et al. 1999, Stempel 2003, Krippendorf 2004), and has been applied to many environment and wildlife research questions (e.g., Miller 1997, Bengston et al. 1999, Bissionault et al. 2005, Gore et al. 2005, Raghavan 2008, Houston et al. 2010, Jacobson et al. 2011). By systematic, we refer to the process whereby articles are read, and a consistent set of selection, sorting and coding rules are applied to text (words, phrases) over multiple reviews of 
the same articles. Media content analysis has proven to be a reliable approach to identifying themes in public discourse (Stempel 2003, Krippendorf 2004). In fact, researchers have gone as far as to suggest content analysis may be substituted for attitude surveys and opinion polls.

Beyond the depth and breadth of data provide by the media through articles, the media have a vital role to play in shaping human perceptions of and our ability to co-exist with wildlife (Wolch 2002, Freeman et al. 2011). "In addition to describing facts and events, texts often communicate information about the attitude of the writer or various participants towards an event being described" (Polanyi and Zaenen 2004, p.1). Perceptions about coyotes are no exception. The lexical choice of the writer used to convey information about coyotes can influence people's emotional responses, perceptions and management consequences (Fraser et al. 2006, Draheim et al. 2011). We acknowledge that newspapers and journalists often depend upon negative stories to sell papers, and hence, portrayals of coyote events are likely to be negative rather than positive. However, our intent here was not determine how each media characterization directly affected public perceptions about coyotes, but to explore the key ways journalists' characterization of coyotes may amplify negative perceptions or stereotypes of coyotes. Overly negative or sensational portrayal of coyote-human interactions has the potential to influence public beliefs in a way that could be detrimental to coexistence. Perhaps more critically, a single negative encounter with a wild animal in an urban setting can increase negative attitudes (Herberlein and Ericcson 2008). Below, we provide an examination of the way coyotes are portrayed in the media. An over arching aim is to help the media, educators, scientists or managers to be aware of the ways in which coyotes and their relationship to people may be unfairly or prejudicially represented.

\section{METHODS}

We searched digital archives of Canadian newspapers published between 1 January 1995 and 31 December 2010. Screening documents for titles that included the word "coyote", we found approximately 30,000 articles, many of which were not about coyotes in Canada or Canis latrans. Hence, we applied constraint terms to narrow our search. These terms consisted of words that were commonly found in titles of articles that were not about the animal coyotes or did not occur in Canada. Common words were found by manually reading thousands of titles, which yielded the following constraint terms: Phoenix, Hockey, USA, Mexico, and Afghanistan. By removing articles with the words Phoenix, and hockey in the titles, we removed a majority of articles about the Phoenix Coyotes hockey team. Removing articles with the word USA in titles helped to isolate Canadian events; likewise, those with Mexico in the title were removed, and helped to eliminate articles dealing with human trafficking from Mexico by "Coyotes" into the USA. The word Afghanistan was frequently found in association with the word coyote (from 2001 onwards) due to the use of a Canadian military forces vehicle, the Coyote. The application of these constraint terms reduced our article set to approximately 3,000 items. We then vetted these titles manually to remove any additional non-target articles. The result was 1,214 articles with none dated prior to 1998 . From these, we extracted 453 primary articles related to humancoyote events in or related to urban centers. We defined primary articles as the first printed report of an interaction with a coyote. Secondary articles (subsequent reprints and follow up reports), editorials, letters to the editor and articles solely addressing agricultural/rural coyote 
interaction were not included here. Primary articles were imported for analysis into NVivo 9 content analysis software (QSR International 1999-2010).

We employed an inductive approach to data analysis, which we based in grounded theory (Strauss and Corbin 1990). Grounded theory, as applied to content analysis, facilitates the emergence of important themes and explanations from a case dataset (i.e., our collection or print media articles) without a-priori hypotheses (Charmaz 2000). As such, our only a-priori categories included "type of interaction", "date", "location", and "location details" as our initial sorting conditions. In the present analysis the grounded theory applied to the case dataset identified important concepts (e.g., characterization of coyotes and coyote behavior, what types of emotional responses were reported) and helped explain the relationships between concepts. These themes may be qualitatively or quantitatively described. For example, Raghavan (2008) used media content analysis to quantify the number of fatal dog attacks in Canada, but clarifies that knowing precise fatality rates may be less useful than understanding which dogs tend to attack, how they attack and the description of events that precipitate, precede, or mitigate attacks. In this paper, the term attack describes encounters that result in a person or pet being bitten by a coyote. We use "direct encounter" to describe any event where a coyote and human or pet are in close range or in contact (e.g., a sighting or being followed by a coyote).

We used an open coding, multiple-pass approach, in which themes were identified by reading, then copying notable words, phrases, concepts, events, or descriptions into new code categories associated with news themes as they emerged. This multi-pass approach facilitated removal/addition/merging of nodes. For example, a first pass through articles may begin with one category called "incident" and determine over time that there is sufficient evidence to have multiple incident types (e.g., "cat", "dog", "human", other"). We applied a constant comparative procedure (Cresswell and Maietta 2002) to three full iterations of reading the articles. We identified descriptive words, phrases, and the lexical approach (Polanyi and Zaenen 2004) used by the media in the portrayal of coyote-human interactions.

The iterative coding was applied to the 453 articles about urban coyote interactions and resulted in a consistent set of information categories, including: 1) summary of incident type, 2) description of coyotes (single words and phrases), 3) description of coyotes killing pets versus humans killing or fighting with coyotes (words and phrases), 4) criminalization of coyote behavior, 5) human emotional experiences reported (fear, sadness, anger, frustration with agencies), and 6) assumptions about coyotes in cities and in Canada (public and experts).

In category 1, we summarized the frequency of each type of event: coyote sighting, coyote-human, coyote-dog, coyote-cat, and coyote-other. For category 2 we tallied individual words, and qualitatively explored the word clusters that were used by media to describe coyotes or their behavior. In category 3 we compared the language and words used to describe how coyotes kill or attack people or pets, in contrast to the words used to describe how humans kill coyotes. In addition, we explored how the media characterized humans that had been attacked (e.g., language describing victimization). Category 4 provides qualitative examples of a recent trend for media to portray coyotes in cities as criminals; although related to category 2 , the prevalence of this theme justified its isolation. Category 5 includes the kinds of emotional experiences portrayed in response to coyote interactions (attack or other), in order of frequency 
of reports by emotional category. These experiences were identified by the words and phrases (e.g., the woman feared for her life), or those attributed to observers and victims (e.g., I am afraid for my children and pets). Due to the high occurrence of 'fear' as an emotion expressed in the articles, we explored and quantified the emergent subcategories. The category "trauma" was included to describe the consequence of fear or loss. Two other themes emerged that relate to emotions and perceptions: 1) animal welfare concerns and, 2) frustration due to lack of agency response. Lastly, in category 6 we identified some assumptions about coyote distribution and occurrence that provide key areas to target education.

\section{RESULTS}

\section{Category 1: Summary of Incident}

Of the 453 articles, 102 were about sightings, 119 described coyote-human interactions (26 were classified as attacks), 108 reported coyote-dog events, 88 explored or described culling events in Canada, 34 were about coyote-cat encounters, and 2 described situations where coyotes led humans to human corpses. We explored the human and pet interactions with coyotes in detail in a separate paper (Alexander and Quinn 2011). Articles about sightings refer to those that describe a simple observation of a coyote. For example, a coyote was seen walking down the street, in a yard, or at a school. In the previous case there was no "conflict" or contact between people, pets and coyotes. Coyote-human and coyote-pet interactions (dog and cat) refer to interactions where there was either a direct interaction (i.e., close contact such as following a person) or an attack (i.e., biting). Coyote control/cull articles describe or detail responses to various culls that were implemented during the period of time examined (1995-2010). Lastly, the category "coyote leads to dead body" was kept separate because these seemed to be unusual cases of human-coyote interactions. In one case, several coyotes were described (by police) to have been approaching and investigating a dead person in a back-alley of Vancouver. In the second case, a woman on horseback was drawn to an area by coyote howls and subsequently found coyotes around the skeletal remains of a woman.

\section{Category 2: Description of Coyotes (Words and Phrases)}

Coyotes in cities that are involved in an interaction with humans or pets are described to have "attacked" in 185 articles, with 272 references to attack(ed/ing) and three using the word maul. The other most common words (and their frequency of occurrence) used to describe coyotes in cities were:

- $\quad$ bold (19)

- brazen (16)

- wiley (15)

- mangy (6)

- nuisance (5)

- $\quad$ wild (3)

- $\operatorname{vicious}(3)$ 
Other words were used less than 3 times, but we suggest they might be aggregated into thematic clusters as follows:

- coyotes are like a disease or a pose a disease risk (infestation, threat, spread disease, diseased, pests, plague, running rampant, sickly)

- coyotes exhibiting aggressive or unusual behavior (violent, stalking, aggressive, brash, lurking, alarming, stealthy, prowling, harassing, menacing, aggressive, nervy, savage, killers, unbelievable)

- coyote appearance (scruffy, fox like, German Shepherd-like, wild, rugged)

- coyote role or effect on people or pets in cities (nuisance, problem, unnerving, pests, intruders, invaders, like rats).

\section{Category 3: Contrasting Media Portrayal of Human and Coyote Behavior during Interactions}

The media portrayal of humans killing, trapping, or fighting coyotes can be contrasted with descriptions of coyotes attempting to bite or biting people or pets. The following quotations provide a range of words and phrases used to describe coyote behavior during interactions with people and pets:

- he [the coyote] tore a cat to pieces

- shocked witnesses watched in horror as the animal went in for the kill

- they feast on small prey

- terrorize pets

- chomped on [a pet]

- the pet died violently

- it was a narrow escape for the dog

- the coyote claimed the life of a puppy

- he's [coyote] got one purpose - to hunt cats

- they wreak havoc

- he left the cat with guts hanging out

- engaged in a rash of killings

- ravaged the pet

- left yard strewn with tufts of cat fur and intestines

- necks ripped open, and ribs picked clean

- ripped apart the dog

- viciously attacked and savaged a cat

- attack everything that moves

- they go into "attack mode".

In contrast, the human involved in an interaction was described as follows:

- the coyote struck the brave mother and drove her glasses into her nose

- the woman was bloodied and frightened

- she came face to face with an aggressive coyote 
- faced off with the coyote

- it sunk its' fangs into Kayla's left arm

- they are so crafty they've learned to scare children to take what they want

- they are coming dangerously close to homes

- he was confronted by a coyote.

One woman reportedly described herself as having "engaged in hand to hand combat with a coyote". One story highlighted a 10 year old boy in Edmonton being awarded a Bronze Medal for Bravery, after kicking and scaring away a coyote that was reported to have come into the yard to attack him and another 10 year old boy. In relation to the act of killing, humans that were described to have:

- culled

- put down

- dispatch

- destroy

- euthanize

- regrettable event

- form of pest control

- deal with the problem

- deal with the pests

- reduce numbers

- put a bounty on them

- done a kindness to thin the numbers

- cut down population

- offer an incentive program

- implement a death sentence.

The method a human used when killing or taking action against a coyote was described as follows:

- mission accomplished

- [the coyote] was hit [by the bullet] but not dead

- tracked and killed

- shot and killed

- shot and trapped

- they [people] are sharpening knives and hatchets

- snared

- trapped.

Phrases about killing coyotes that show a lack of respect for animals and animal welfare included: "they were hunted into submission", and "'he was finished off with a hammer". In killing contests and culls, hunters/trappers were asked to "bring in the ears only", or that "four paws must be presented". The Osgood, Ontario Great Coyote Contest was sponsored by a private retail company, which described the number of dead coyotes arriving at their shop as "a 
back log of dead coyotes at the door". Finally, one article borrows from old stereotypes and states that "for lack of an Acme anvil or a deep canyon, they put down a box trap".

\section{Category 4: Portrayal of Coyotes as Criminals}

We observed a recent trend (post 2006), to use words and phrases generally reserved for the description of criminal behavior in humans:

- like brazen bandits engaged in daytime kidnappings and robberies

- the two assailants [coyotes] remain at large

- the prime suspect: Wiley coyote, the coyote wanted for questioning in the deaths of 2 west end cats

- coyote remains a fugitive

- it [coyote] escaped and is still on the loose

- the brazen intruders

- [coyote] outruns and outfoxes authority

- they flee on foot

- engaged in unprovoked violence

- they are roaming around playgrounds...lurking in bushes.

In a related trend, the public reportedly stated:

- coyotes train pups to squeeze through balcony railings in pursuit of cats dogs or the occasional parakeet

- coyotes are prowling the neighbourhood

- snatching dogs and cats

- they are evil dogs and don't have souls.

\section{Category 5: Human Emotional Experience}

Five themes describing human emotions emerged and were consistent with universal emotions described by Eckman (2003) and Darwin (1872). These emotional response themes were identified by words used to express the emotion (e.g., I was scared) or inferred by description of events or people (e.g., she lost her beloved cat, he was like a child to her [and the coyote killed him]). The emotional themes observed included: fear/surprise, sadness/loss, and others: anger, disgust, and joy.

\section{Fear/Surprise}

The principal emotion reported by media to be experienced by people was fear. In 147 (32.4\%) articles there were 187 references to fear arising from the presence of coyotes or an incident with coyotes. Forty-four $(9.7 \%)$ articles contained 51 references to fear of disease in coyotes that could affect pets or people. Fear for children's safety was raised in $73(16.1 \%)$ articles. Fear for children extended from one's own children to fear for daycares and schools, in general. Examples of fear statements made by the public included: 
- I am afraid to let my kids out

- the children are at risk

- will it take a child being killed before they do something

- I don't let my kids out in the yard anymore.

Fear for self, or others (general public), was found in 35 (7.7\%) articles. In these cases, people make statements, such as:

- I am afraid to go outside

- I am afraid to walk alone

- people are not safe anymore.

Fear for pets was expressed in $43(9.5 \%)$ articles, in which people state they were:

- afraid to let pets out in the yard

- afraid to let pets out of their sight

- afraid to walk on their usual trails

- have posted warning to other pet owners to be aware

- afraid they cannot recover from the loss of their pet.

People stated they were also concerned that they or their pets would contract rabies, mange, and Giardia (i.e., beaver fever) in $44(9.7 \%)$ articles. Rabies was exclusively mentioned in British Columbia and Ontario. Only two articles reported disease incidence: one article quoted experts who said that there had been 20 positive cases of rabies in Ontario in 2001, and another quoted experts that there was no evidence of rabies in the Yukon coyote population.

\section{Sadness/Grief}

While fear was the dominant reported emotion, sadness/grief was also indicated in some articles. No direct statements were found about being sad or grieving; however, 17 (3.7\%) articles allowed inference for sadness/grief by the nature of the comments used (e.g., "he was her beloved cat", "the memorial service was a somber affair"). The expressions of sadness and grief were particularly evident for adults who had pets killed by coyotes, but not so for adults that had been bitten or observed their children bitten by coyotes. In the latter case, people expressed anger at management agencies and coyotes, not sadness or grief about the event. One notable exception was the mother of a young woman who was killed by coyotes in Nova Scotia, in October 2009; she expressed her grief at the loss of her daughter and denounced the retaliatory cull of coyotes.

There were 56 articles (12.4\%) with 66 references to pets by their name (e.g. Fifi, Coco). There were $91(20.0 \%)$ articles describing a direct interaction between a dog-coyote, and 30 (6.6\%) involving cat-coyote (Alexander and Quinn 2011). Direct evidence that the magnitude of loss was large, and that pets were considered to be family members was based on statements by the public:

- the cat has been her baby 
- Fifi was like my baby

- he's like our child

- she's my baby

- he's like a member of the family

- it is a great loss for our family

- the $108 \mathrm{lb}$ companion who had yet to celebrate his $2^{\text {nd }}$ birthday [was killed]

- they held a memorial service for the dog

- Rocky the beloved pet

- her beloved Zoe

- he [dog] was recovering from invasive surgery...and is still quite shaken

- as a result of the injury "my Sunny is on sick leave".

\section{Trauma}

Trauma was reported in $28(6.2 \%)$ of cases where a human watched their pet be killed by coyotes. Indirect evidence of trauma included multiple descriptions of a person's health in terms of:

- anxiety

- inability to sleep or insomnia

- overwhelming fear

- fear to go outside to walk

- fear to go into yard

- fear for children or pets going outside

- feeling like a prisoner in their own home (multiple statements of this)

- feeling vulnerable and unable to protect oneself

- being in shock

- feeling panicked

- feel like there is evil lurking in every bush

- stating "it was traumatic"

- cannot go out without some type of protection (e.g., pepper spray)

- feeling paranoid and have to be more vigilant

- experienced changes in behavior (e.g., avoiding walking on trails or in parks).

While these words from newspapers cannot be used diagnostically, they are indicative of traumatic response to an external event (Schiraldi 2000). Notably, there was one instance of direct evidence (with multiple citations in different articles) where an individual claimed to have been diagnosed with (PTSD) after witnessing the death of a cat.

\section{Other Emotions: Anger, Disgust, and Happiness}

These three additional emotions (anger, disgust, happiness) were expressed and identified as a theme, but the numbers of articles relating to each was relatively low $(<10$ articles for each category). Statements that depicted anger were directed at agencies and coyotes. Examples of the former include: "this should not have happened, when will they do something, I'll take it into 
my own hands". Statements showing the anger towards coyotes include: "they [coyotes] don't deserve to live" and "coyotes should be killed if they hurt a pet".

Evidence of disgust (Johansson and Karlsson 2011) was inferred from descriptions of coyotes as follows:

- a plague

- an infestation

- like rats

- $\quad$ spread disease.

Reports of disgusting acts against coyotes were observed, including: a mutilated coyote was found in a bag at York University campus, and a mutilated coyotes was hung outside the door of a Bed and Breakfast after the owner wrote a letter denouncing the coyote cull (2009).

Positive valence was found in very few primary news stories, which was not unexpected given general newspaper reporting trends towards the negative and dramatic. An example was enjoyment described through several statements, such as:

- we love to watch the coyotes

- they are our entertainment

- we enjoy listening to coyotes.

\section{Concern for Animal Welfare as Related to Coyotes}

Concern for animal welfare was expressed through individual statements in $<20$ articles, and included:

- reluctant to call the agencies for fear that the coyote would be killed

- coyote culls are an an act of cruelty

- feeling sick after seeing a coyote killed.

Other evidence showed concern for the health of coyotes, referring to a "the poor mangy coyote" or indicating that "I don't want the coyotes to suffer". One woman tried to rescue an injured coyote after it was hit by a car, and she was bitten. Some citizens raised concern for displacement of coyotes, stating that: "we've encroached into their habitat" and "we have to share the world even if we don't like coyotes".

\section{Frustration Articulated about the Lack of Response by Agency}

Thirty articles (6.6\%), yielded 38 references about citizens who perceived they were ignored by agencies, experienced a lack of response from agencies, not clear who has jurisdiction, or could not find centralized information to learn to co-exist. A theme emerged that people are confused about who is responsible for coyotes, and perceived that agencies "pass the buck" routinely to other agencies. For example, in Calgary, a resident was quoted as saying that Alberta Fish and Wildlife told him coyotes are not a priority for officers and he was referred to City of Calgary, 
who indicated they had no jurisdiction to manage coyotes and referred him to Fish and Wildlife. Another individual from Toronto, Ontario stated: "The humane society won't remove it, the SPCA won't remove it, Fish and Wildlife won't remove it, the City won't remove it, why wasn't this done before a child was attacked?" Statements indicating frustration include variants on the following statements:

- when are you going to do something

- we are frustrated by a lack of clear information on how to deal with coyotes

- I contacted the mayor but was referred elsewhere

- just get rid of them - it is your job

- conservation officers do not return calls

- [the government] always answer with 'well, we live in Canada and there is nothing we can do about it'

- I received no help from any agency

- the ministry had a flippant response

- [Government] have a complete hands off approach, there is not enough done to make people aware...why isn't there a sign?

- I'm frustrated - it took me 30 minutes to get a response

- I'm upset no-one will do anything

- I'm not taken seriously, wildlife officials don't see the problem, they dropped the ball, I don't anticipate any results, they did nothing

- We need more conservation officers.

\section{Category 6: Assumptions about Coyotes}

Several key assumptions were identified and discussed below. Some of these, particularly the distribution of coyotes and the extent of hybridization are topics of great debate in current literature. We present these as potential areas that require better dissemination of information on the topics, or highlight areas where there is a need for greater research and understanding.

\section{Coyotes are Recent Immigrants to Canada}

Several articles described the current and historic distribution of coyotes in Canada and the coterminous United States. There was an assumption that coyotes are not from Canada but have migrated in from the south and west, following the European fur trade settlement patterns. The notion that coyotes are newcomers to many provinces in Canada was evident. Without verification, articles make specific reference to when coyotes arrived in specific provinces. In one article coyotes were said to have been present in Ontario for over 100 years. Another article stated that coyotes did not exist in New Brunswick until the 1950s. Coyotes were identified as recent immigrants to the west coast of British Columbia and to have arrived in Vancouver in the early 1980s. Another article stated that coyotes are recent phenomena in cities, with the "first reported incidents in cities" occurring only 15 years ago. 
Coyotes were considered to have invaded cities and their populations are presented (without factual verification by reporters) to be:

- increasing in numbers and distribution, out of control

- growing unchecked for years

- experiencing a boom.

\section{Coyotes in Eastern Canada are Hybridized with Dogs and/or Wolves}

A common perception is that coyote numbers are increasing, and many coyotes are hybridizing with dogs (coydogs) and wolves in Eastern Canada. It was also suggested in several articles that through the expansion, coyotes have interbred with wolves as they move to the east, which has resulted in a much larger coyote. Without any documented evidence, one article stated that coydogs are much more common in cities.

\section{Coyotes are Unnatural in Cities}

While statements indicated the public and experts both understand coyotes to be a natural part of an urban ecosystem, and that cities have in many cases been built around existing coyote habitat, there are many statements that suggest a lack of understanding of the ways in which coyotes may become part of the urban environment. Experts were identified and aggregated as a group, including: government biologists or managers (federal, provincial), university faculty in related biological field, or private sector biologists/ecologists. We acknowledge these individuals may have different levels of "actual" expertise with respect to coyote ecology and biology; however, we chose these as an aggregate, because they were the "experts" chosen by the media and advice tended to be similar. Expert opinion was cited in 324 of $453(71.5 \%)$ of articles, and advice included:

- co-existence is necessary

- lethal control is not an effective long term strategy

- coyotes are behaving normally when they hunt in cities

- feeding coyotes leads to habituation

- coyotes have an important role in urban ecosystems.

While most experts articulated that co-existence was the best/only option, there was one notable exception: a professor at the University of British Columbia reportedly stated that, “...wild predators cannot peacefully co-exist with people and pets. They eat meat and they don't have the ability to march into McDonald's drive through, so they have to kill it".

We also found statements by public and experts alike that portrayed coyotes as not 'natural' in cities, including:

- coyotes invaded cities 15 years ago

- a coyote in the city is most likely an outcast

- coyotes have adapted to cities

- the coyote is a migrant into cities from the American Southwest 
- most are smart enough to stay where they belong - usually they stay in the woods

- they can thrive in the urban fringes

- they have infiltrated cities

- coyotes are prowling neighborhoods [like] brazen intruders.

Some phrases indicated that the public perceives behavior that is "natural" in the wild, such as hunting prey, to be "unnatural" when it occurs in the city. The concept was portrayed in the descriptions of the results of coyotes hunting in cities:

- the horrific sight was a dead deer in the city killed by coyotes

- the coyote ravaged a dead rabbit

- he ripped apart a $\$ 500$ Pomeranian dog.

Lastly, there was a sense of powerlessness in the descriptions of coyotes in cities:

- we are fighting a losing battle

- Toronto has become coyote country

- there is nothing they are afraid of

- coyotes are brazen intruders in the city.

\section{Coyotes Pose a Great Risk to the Safety of Canadians}

As evidenced by the expression of fear for self, children or pets and the stated rationale for widespread culls within some Canadian provinces, coyotes are un-necessarily targeted as posing a great risk to people, children and pets. Experts attempted to address these concerns by providing a context for the risk of a coyote bite, relative to other common injuries: For instance, experts noted the number of times humans are bitten by dogs each year far exceeds those bitten by coyotes (e.g., over 300,000 dog bites per year in Canada), that the number of injuries occurring in homes each year (e.g., hundreds of children's death by poisoning or insect stings), or the safety of recreational activities, such as skiing or driving ATVs far exceed the injuries sustained by contact with coyotes (approximately 3 bites per year) (Alexander and Quinn 2011).

\section{DISCUSSION}

\section{Categories 1-4: Media Portrayal of Coyotes}

This paper was not designed to test whether or not negative portrayal of coyotes increases negative sentiment in the public, but to examine the ways in which the media may negatively stereotype these animals and their interactions with people. The majority of articles reviewed for this paper were stories of interactions between coyotes, people and pets that were deemed negative by the human participants. The focus on primary articles herein indicated a potential selection by the print media for negative encounters as compelling news. Subsequent analysis of secondary articles and letters to the editor may help to address public response to this apparent bias. Adjectives and descriptors applied to coyotes were often directed at debasing the character of the animal (e.g., brazen, wily, vicious and menacing). The lexical choices reported here reflect a highly judgmental, prejudicial and stereotypical narrative with respect to coyotes. 
Firstly, the word choice is inflammatory, and secondly the behavior of a few individuals is quickly and easily transferred to coyotes as a species. This is particularly important in the depiction of coyotes as somehow "infesting", "invading", and "marauding", when the actual risk of a coyote biting a human in Canada is remarkably low (i.e., less than 3 attacks per year over 10 years). These narrow and misleading portrayals of coyotes can foster and perpetuate misunderstanding, fear, and negative attitudes toward coyotes (Freeman et al. 2011).

This may be exacerbated when the media uses disparate portrayals of coyotes relative to human behavior when the two species interact. Loaded descriptions of coyotes leaving people bloodied, frightened and in shock, or "confronting" people stands in stark contrast to portrayals of people killing coyotes. Rather than humans attacking, dismembering or killing coyotes, the terminology used is euphemistic and highly sanitized (i.e., people "cull" or "remove" coyotes). Details of the remains after a coyote kill only serve to provoke public sentiment that coyotes are cruel, "leaving guts hanging out" and "ravaging pets". The portrayal again is highly prejudicial and could suggest malicious intent on the part of the coyote (Peterson et al. 2010). Despite the fact that a bullet to the stomach or head might render a coyote "ripped apart", "bloodied", with "guts hanging" out, the media chooses to describe premeditated human acts as "dispatching" or "euthanizing" a coyote. Similarly, acts that humans inflict upon coyotes when they kill it, or after they kill it show great lack of respect for the animal or notions of superiority (Freeman et al. 2011). For example, coyotes were described to have been "hunted to submission". General fear might be invoked in the public when individuals describe themselves as "sharpening their knives and hatchets", implying they are at war against a threat to public safety - the coyote.

The depiction of coyotes also incorrectly implies a type of conscious and premeditated malevolent behavior on the part of coyotes (Peterson et al. 2009). Rarely is the behavior described in ecological terms of predation. The language is reminiscent of that used to describe premeditated attacks on people by other people. In the case of people killing other people, perpetrators are protected by laws that prohibit stereotyping by ethnicity or appearance, but in the case of coyotes there is no opportunity for this distinction. Once portrayed as a killer, the description extends from the individual coyote to the species by virtue of their perceived similarity; that is, the conclusion that "a coyote is a coyote" is easy to draw, if one has not had personal experience with many coyotes or studied animal behavior.

Moreover, language selection in the articles analyzed for this research indicate a trend to criminalize the actions of coyotes in cities, or to describe the events that follow in words typical of the pursuit and arrest of criminals. As the language used by the media influences the beliefs of people (Draheim et al. 2011), especially in the case of coyotes, the descriptions of basic behavior of coyotes in language that portrays criminal acts, can only create and perpetuate stereotypes of coyotes as actively undertaking acts against people (Freeman et al. 2011, Peterson et al. 2010)

The public relies on the media for information regarding socially relevant issues, including information about urban ecology and wildlife (Freeman et al. 2011). The information in media reports both reflects and influences the attitudes of people towards coyotes (Draheim et al. 2011). As such, journalistic standards require subject matter to be portrayed in a fair and 
balanced way that neither stereotypes nor creates prejudice against those involved (Freeman et al. 2011).

\section{Category 5: The Human Emotional Experience}

Emotional reactions to coyotes can be varied and intense (Draheim et al. 2011, Jacobs 2009). The present analysis examined the reflective experiences of people as portrayed through the selective lens of the media. We acknowledge that the media select which emotions to portray to produce a "good story". Thus, the themes that emerged from the articles were used to identify the dominant emotions surrounding coyote interactions with people and pets, rather than to quantify how frequently each emotion is experienced and by whom. The experiences within each of these emotional classes were described and yielded information vital to helping managers, scientists, and conservationists understand what people need to improve coexistence with coyotes.

Fear was the most frequently described as: fear for self, fear for children, fear for pets, and fear of disease. Johansson and Karlsson (2011) explain that the primary reason people fear predatory animals is a fear of harm and pain; unlike fear of non-predatory animals where the fear relates mostly to contamination. Statements reported herein suggest coyotes are feared for both reasons; coyotes are perceived to be a physical threat through biting or killing, and a health threat through transfer of disease. Johansson and Karlsson (2011) also suggest that large carnivores are feared for their size. Interestingly, our analysis showed that people often reported coyotes as being much larger than they actually are (e.g., reported to be German Shepherd sized).

Importantly, "the experience of fear varies" and can be influenced by several factors including perception and uncertainty of one's own reactions (Johansson and Karlsson 2011). As such, the media portrayal of the effects of an interaction should more clearly depict the actual risk, the noted extent of injury, provide context for other risks, and help the public understand the range of choices in behavior that exist with respect to coyotes. Fear based on lack of experience with coyotes may be rectified to some degree with information and correct portrayal of risk. In contrast, the inappropriate depiction of risk can instill fear in the public and result in inappropriate management responses.

People viewed the loss of pets as a sad and significant, often traumatic event. Hence, it is important to understand that they feel discouraged, frustrated, belittled and abandoned by the agencies charged with managing coyotes or responding to complaints. Management agencies can inadvertently create greater frustration and anger by invalidating the significance of a coyote killing a pet. Unfortunately, this can and has led to people taking action on their own or advocating widespread killing of coyotes. Two cases illustrate such responses: One individual erected a $2.5 \mathrm{~m}$ high fence, $100 \mathrm{~m}$ in length, to surround their house and protect their family from coyotes; another built a $1.8 \mathrm{~m}$ high solid wood and cement fence around the house at a cost of $\$ 80,000.00$ (CND). In another case, a Vancouver resident launched a campaign against coyotes that included suing the City of Vancouver and the Province of British Columbia for negligence and enacting a policy to co-exist with coyotes that violated her rights to a safe environment. This individual has become a constant voice rallying support through media and public presentation to eradicate coyotes (Webster 2007). 


\section{Trauma}

There was sufficient reference to being "traumatized" by a negative coyote interaction to warrant inclusion as a theme. Both symptoms and diagnoses showed strong evidence that many people suffered symptoms consistent with trauma (Schiraldi 2000). As such, lack validation of the level of grief, sadness or fear by agencies likely will continue to foster "frustration", "anger", or feelings of being "betrayed" by authorities. This frustration, in turn, may be redirected toward coyotes and calls for their eradication in cities. There is a strong need for responding agencies to acknowledge the loss of animals as significant to the individuals.

\section{Other Emotions: Anger/Disgust/Happiness}

The lower frequency of statements depicting these emotions does not imply they are of unequal importance, as they more likely reflect a choice by the media to focus on more sensational emotions. From the perspective of balanced reporting, it may be useful to include more positive emotional statements associated with coyotes, which may in turn improve public perception of the species (Draheim et al. 2010). Depicting how and why individuals get angry or why they find coyotes disgusting (i.e., disease carriers) may be helpful for improving efforts to co-exist and public-agency relationships. Perhaps more importantly, efforts need to be made to provide factual medical information as to the actual types or risks of various infections posed by the presence of coyotes. In a related article, Watts and Alexander (in review, CATE, 2011) describe the constituent parasites in urban and rural fecal samples in the Calgary region, which may provide a basis for understanding the previous risks. In addition, more media coverage of positive interactions and the reflection of positive emotions regarding coyotes would provide a more balanced narrative. The public also expressed anger and frustration towards management agencies for a variety of reasons. Identifying clear lines of authority, creating information websites (e.g., Living with Coyotes: www.rockies.ca/coyotes, among others), providing targeted education, and dedicating agency resources to response and prevention of coyote interactions may improve the situation.

\section{Category 6: Assumptions about Coyotes}

Most of the assumptions about coyotes portrayed in the articles can be classified as attempts to cast the coyote as 'out of place' in urban areas or as a source of contamination that threatens order (Douglas 1966). In either case, the narrative reinforces the nature-culture dualism that characterizes conceptions of urban and non-urban or civilized and wild (Evernden 1985, Sabloff 2001). The coyote, a wild carnivore in an urban setting, challenges the modernist conceptions the "proper, morally appropriate, spatial relations between animals and society" (Jerolmack 2008, p. 73). It is the 'wildness' juxtaposed against the supposed order of the metropolis that arises as problematic here. As Livingston (1994) explains:

Wildness receives a good deal of pejorative treatment in our society. It connotes desolation (usually meaning the absence of people), as well as barbarous savagery and all else that toes with the "primitive" condition, perhaps especially chaotic unpredictability and uncontrollability, both of which are anathema to all of the organizing principles of our technoculture. To be wild is to be ungovernable, which means uncivilized (p. 5). 
It is simply deemed 'unnatural' for coyotes to occupy North American cities. Fine and Christoforides (1991) demonstrate the challenges that ensue when an urban wildlife species (the English Sparrow) is defined as: 1) a foreigner, 2) that competes unfairly with other species, 3) that has an immoral character, and 4) needs to be eliminated from the community (see also Jerolmack, 2008 on pigeons and rats). The co-existence of people and coyotes will require further examination of how these relationships are cast and received in public discourse.

\section{CONCLUSIONS}

Direct interaction between coyotes, people and pets draws considerable attention in the popular media and provides one window into understanding the nature of human-wildlife relationships in urban areas. Primary news articles reviewed from the recent Canadian print media predominantly focused on negative interactions between humans and coyotes. The portrayal of coyote behavior was often destructively stereotypical with references to depraved character, malicious intent and criminality. In contrast, human response to address coyote 'problems' was generally sanitized and euphemistic. This public discourse both reflects and influences attitudes and behaviors toward urban coyotes (and urban ecology in general). We suggest that a more balanced approach to reporting is required if coexistence with coyotes is to be less acrimonious in urban settings. Moreover, we concur with Freeman et al. (2011) that "journalists should use less biased, non-objectifying language, and seek out appropriate human experts who do not have a vested interest in animal use and can advocate for their interests" (p. 13). For example, along with addressing the language in news reports of negative human-coyote encounters, we recommend that the media consider running stories on positive encounters with coyotes and urban wildlife so as not to bias public sentiment through a focus on negative interactions. While it is possible that changing how coyotes are portrayed in the media may not directly lead to coexistence, the media does have a role to play in moderating the risk people associate with coyotes.

The complex social-ecological systems that define urban ecosystems will continue to include the highly adaptable coyote. Education and proactive management intervention will be required to ensure an acceptable level of coexistence between people and coyotes. The potential for interactions causing significant injury or fatalities results in real fears amongst the public. The control and supervision of pets and children in urban protected areas requires active intervention by park managers and greater awareness and knowledge from park users. Urban ecology authorities need to work along with the media to ensure that useful and accurate information is being communicated to the public on these issues. Examination of media content provides a mechanism for wildlife authorities and environmental managers to gauge and respond to public sentiment.

In addition, $6.2 \%$ of pet owners report symptoms of traumatic responses (and in one case PTSD), which raises some important management implications surrounding the response or handling of these incidents. Humans now view pets as family members and thereby the loss of the animal has the significance of a loss of a child to some individuals. As a result, response by agencies should reflect a level of concern for these losses and address the issue with appropriate regard. Despite the difficulty in relating to this condition for all involved, the loss is real for the 
individual. Again, how these issues are addressed by the authorities and how they are reported by the media is extremely important.

Finally, if society is truly committed to the design and management of urban spaces so as to enhance rather than detract ecosystem function (Steiner 2011), then we need to address the nature-culture apartheid that is revealed in the narratives exemplified in the material reviewed for this paper. As Sandlos (1998) notes:

in an important sense, the coyote's survival represents an evocative challenge to the ordered and developed world imagined by advocates of human-centred progress, and offers North America's colonizers an alternative conceptual space to live in association with, rather than against a spontaneous and ecstatic vision of wild nature (p. 51).

\section{LITERATURE CITED}

Alexander, S.M. and M.S. Quinn. 2011. Coyote (Canis latrans) interactions with humans and pets reported in the Canadian print media (1995-2010). Human Dimensions of Wildlife $16: 345-359$.

Alberti, M. 2008. Advances in urban ecology. Springer, New York.

Baker R.O. and R.M. Timm 1998. Management of conflicts between urban coyotes and humans in southern California. Pages 299-312 in Baker R.O., Crabb A.C., eds. Proceedings of the $18^{\text {th }}$ Vertebrate Pest Conference; 2-5 March, Davis, CA.

Baruch-Mordo, S., S.W. Breck, K.R. Wilson, and J. Broderick. 2009. A tool box half full: how social science can help solve human-wildlife conflict. Human Dimensions of Wildlife $14: 219-223$.

Bekoff, M. and S.M. Bexell. 2010. Ignoring nature: why we do it, the dire consequences, and the need for a paradigm shift to save animals, habitats and ourselves. Human Ecology Review 17:70-74.

Bekoff, M. and E.M. Gese. 2003. Coyote (Canis latrans). In: Feldhamer G.A., Thompson B.C. and Chapman J.A. (eds). Wild mammals of North America: biology, management. Baltimore, MD: Johns Hopkins University Press.

Bengston, D.N., D.P. Fan and D.N. Celarier 1999. A new approach to monitoring the social environment for natural resource management and policy: The case of US national forest benefits and values. Journal of Environmental Mgmt. 56(3):181-193.

Berger, K.M. 2006. Carnivore-livestock conflicts: effects of subsidized predator control and economic correlates on the sheep industry. Conservation Biology 20:751-761.

Bissionault, M., W. Gladstone, P. Scott, N. Cushing. 2005. Grey nurse shark human interactions and portrayals: A study of newspaper portrayals of the grey nurse shark from 1969-2003

Cadieux, C.L. 1983. Coyotes: predators and survivors. Stone Wall Press, Washington, D.C.

Carbyn, L.N. 1989. Coyote attacks on children in western North America. Wildlife Society Bulletin 17(4), 444-446.

Charmaz, K. 2000. Grounded theory: Objectivist and constructivist methods. In N. K. Denzin and Y. S. Lincoln (Eds.), Handbook of qualitative research (2nd ed., pp. 509-535). Sage, Thousand Oaks, CA..

Clark, T.W., M.B. Rutherford and D. Casey. 2005. Coexisting with large carnivores: lessons from Greater Yellowstone. Island Press, Washington, D.C. 
Cresswell, J.W. and R.C. Maietta. 2002. Qualitative research. In D. C.Miller and N. J. Salkind (Eds.), Handbook of social research (pp. 143-184). Sage, Thousand Oaks, CA.

Crooks, K.R. and M.E. Soule. 1999. Mesopredator release and avifaunal extinctions in a fragmented system. Nature 400:563-566.

Darwin, C. 1872. The expression of the emotions in man and animals (2007 reprint, $2^{\text {nd }}$ ed.). Dover, Mineola, NY.

Decker, D.J., T.L. Brown and W.F. Siemer. 2001. Human dimensions of wildlife management in North America. Bethesda, MD: The Wildlife Society, Maryland.

Dobie, F. 1949. The voice of the coyote. Little, Brown and Company, Boston.

Douglas, M. 1966. Purity and danger: an analysis of the concepts of pollution and taboo. Routledge, London.

Draheim, M.M., L.L. Rockwood, G. Guagnano, and E.C. M. Parsons. 2011. The Impact of information on students' beliefs and attitudes toward coyotes. Human Dimensions of Wildlife: An International Journal 16:67 - 72.

Eckman, P. 2003. Emotions revealed. St. Martin's Griffin, New York.

Evernden, N. The natural alien: humankind and the environment. University of Toronto Press, Toronto.

Faeth, S.H., P.S. Warren, E. Shochat, and W.A. Marussich. 2005. Trophic dynamics in urban communities. BioScience 55: 399-407.

Fine, G.A. and L. Christforides. 1991. Dirty birds, filthy immigrants, and the English Sparrow war: metaphorical linkage in constructing social problems. Symbolic Interaction 14(4): 375-393.

Fox, C.H. and C.M. Papouchis. 2005. Coyotes in our midst: coexisting with an adaptable and resilient carnivore. Animal Protection Institute. Sacramento, CA.

Fraser, J., D. Reiss, P. Boyle, K. Lemcke, J. Sickler, E. Elliott, B. Newman, and S. Gruber. 2006. Dolphins in popular literature and media. Animals and Society 14(4) 321-349

Freeman, C.P., M. Bekoff and S.M. Bexell. 2011. Giving voice to the voiceless. Journalism Studies 12(5): 590-607.

Gehrt, S. 2004. Ecology and Management of Striped Skunks, Raccoons, and Coyotes in Urban Landscapes. Pages 81-104 in Fascione et al., Eds. People and Predators: From Conflict to Coexistence. Washington, DC: Island Press.

Gore, M.L., W.F. Siemer, J.E. Shanahan, D. Schuefele, and D.J. Decker. 2005. Effects on risk perception of media coverage of a black bear-related human fatality. Wildlife Society Bulletin 33:507-516.

Government of Saskatchewan. 2010. Minister's message. URL: http://www.agriculture.gov.sk.ca/agv_June2010_mm (accessed 17 November 2011).

Herberlein, T.A. and G. Ericcson. 2008. Public attitudes and the future of wolves Canis lupus in Sweden. Wildlife Biology 14(3):391-394.

Houston, M.J., J.T. Bruskotter, and D. Fan. 2010. Attitudes toward wolves in the United States and Canada: A content analysis of the print news media, 1999-2008. Human Dimensions of Wildlife 15:389 - 403

Jacobs, M.H. 2009. Why do we like or dislike animals? Human Dimensions of Wildlife 14:1 11.

Jacobson, S.K., C. Langin, J.S. Carlton, and L.L. Kaid. 2011. Content analysis of newspaper coverage of the Florida panther. Conservation Biology [online: http://onlinelibrary.wiley.com/doi/10.1111/j.1523-1739.2011.01750.x/abstract] 
Jerolmack, C. 2008. How pigeons became rats: the cultural-spatial logic of problem animals. Social Problems 55(1):72-94.

Johansson, M. and J. Karlsson. 2011. Subjective experience of fear and the cognitive interpretation of large carnivores. Human Dimensions of Wildlife: An International Journal 16:15 - 29.

Krippendorf, K. 2004. Reliability in content analysis: some common misconceptions and recommendations. Human Communication Research 30:411-433.

Livingston, J.A. 1994. Rogue primate: an exploration of human domestication. Key Porter, Toronto.

Miller, M.M. 1997. Frame mapping and analysis of news coverage of contentious issues. Social Science Computer Review 15(4):367-378.

Peterson, M.N., L.B. Jessie, L. Kirsten, J.P. Markus, and P. Tarla Rai. 2010. Rearticulating the myth of human-wildlife conflict. Conservation Letters 3:74-82.

Piccolo, B.P. 2002. Behaviour and mortality of white-tailed deer neonates in suburban Chicago, Illinois. MSc. Thesis, University of Illinois, Urbana.

Pickett, S., G. Buckley, S. Kaushal, and Y. Williams. 2011a. Social-ecological science in the humane metropolis. Urban ecosystems 14:319-339.

Pickett, S.T.A., M.L. Cadenasso, J.M. Grove, C.G. Boone, P.M. Groffman, E. Irwin, S.S. Kaushal, V. Marshall, B.P. McGrath, C.H. Nilon, R.V. Pouyat, K. Szlavecz, A. Troy, and P. Warren. 2011b. Urban ecological systems: scientific foundations and a decade of progress. Journal of Environmental Management 92:331-362.

Polanyi, L. and A. Zaenen.2004. Contextual valence shifters. In J. Shanahan, Y. Qu, and J. Wiebe (eds.), Computing Attitude and Affect in Text: Theory and Applications, pp. 1-9. The Information Retrieval Series, Vol. 20, Springer, Dordrecht, The Netherlands.

Raghavan, M. 2008. Fatal dog attacks in Canada, 1990-2007. Canadian Veterinary Journal 49:577-581.

Sabloff, A. 2001. Reordering the Natural World. University of Toronto Press, Toronto.

Sandlos, J. 1998. Savage fields: Ideology and the war on the North American coyote. Capitalism Nature Socialism 9(2): 41-51.

Schiraldi, G.R. 2000. The post-traumatic stress disorder sourcebook. McGraw-Hill, Toronton.

Siemer, W.F., Decker, D. J., and Shanahan, J. 2007. Media frames for black bear management stories during issue emergence in New York. Human Dimensions of Wildlife 12:1-12.

Steiner, F. 2011. Landscape ecological urbanism: origins and trajectories. Landscape and Urban Planning 100:333-337.

Stemple, G.H., III. 2003. Content analysis. In G.H. Stemplel III, D.H. Weaer, and G.C. Wilhoit (Eds.), Mass communication research ad theory (pp. 209-219). Boston: Allyn and Bacon.

Strauss, A., and Corbin, J. 1990. Basics of qualitative research: Grounded theory, procedures and techniques. Sage Publications, Newbury Park, CA

Walker, D.E. 1994. Nez Perce coyote tales: the myth cycle. University of Oklahoma Press, Norman, OK.

Wang, X., R.H. Tedfor and M. Anton. 2008. Dogs: their fossil relatives and evolutionary history. Columbia University Press, New York.

Webster, J.C. 2007. Missing cats, stray coyotes: one citizen's perspective. Pp. 437-503 in: Proceedings, 12th Wildlife Damage Management Conference (D. L. Nolte, W. M. Arjo, and D. H. Stalman, Editors). Wildlife Damage Management Working Group of The Wildlife Society, Bethesda, MD. 
White, L.A., and S.D. Gehrt. 2009. Coyote attacks on humans in the United States and Canada. Human Dimensions of Wildlife 14:419-432.

Wolch, J. 2002. Anima urbis. Progress in Human Geography 26:721-742. 